\title{
The Acceptance And Use of Digital Public Service: An Influence of Trust and An Application of UTAUT2
}

\author{
Bunga Dionika $^{1}$, Irwansyah ${ }^{2}$, Mazaya Rizy Safira ${ }^{3}$ \\ \{bungadionikaidris@gmail.com ${ }^{1}$, dr.irwansyah.ma@gmail.com ${ }^{2}$, mazayarizy95@gmail.com ${ }^{3}$ \} \\ Departement of Communication Studies, Faculty of Social and Political Science, Universitas \\ Indonesia, Depok, West Java, Indonesia ${ }^{1,2,3}$
}

\begin{abstract}
The understanding of factors affecting the acceptance of technology is a crucial step to indicate its success. Extended The Unified Theory of Acceptance and Use of Technology (UTAUT2) has been tested to analyze the acceptance and use of technology, notably of the use which is aimed to improve organizational efficiency and effectiveness. Government of South Tangerang City has implemented smart city through varied digital public services. Digital public service consists of various applications and sites which enable society to access the information and administrative services. The objective of the study is to analyze the model of UTAUT2 on the acceptance and use of digital public services by inhabitants of South Tangerang City, with trust as additional variable. This study used quantitative approach with quasi-experimental design. The results have shown that the model UTAUT2 cannot be fully applied to the acceptance and use of government's digital public services of South Tangerang City. From seven constructs of the model of UTAUT2, hedonic motivation was the only construct which did not affect the intention of use of this digital public service. As moderator, gender, age and experience did not moderate the exogenous variables towards the entire endogenous variable.
\end{abstract}

Keywords: UTAUT, technology acceptance, use of technology, digital public service, smart city

\section{Introduction}

The acceptance of technology is an essential factor which determines the success or failure of a technology. The chance of further innovation will be more widely opened for the use of technology which has been used more frequently. Innovation which enhances the role and use of technology in our daily life has emerged the dependency on technology. This condition occurs as users have accepted and used the technology.

Some previous studies on related theme have shown the importance of understanding of the acceptance and use of technology [1], [2], [3]. These references have emerged theoretical framework, model and theories related to the acceptance and use of technology with various factors which influences trust, attitude and intention to accept the technology. Extended UTAUT (UTAUT2) is a model which can be fit to analyze the acceptance and use of technology, notably of those aiming to improve organizational efficiency and effectiveness.

Digitalized era has changed the basic aspects on how the government completes their duties towards the society [4]. To create a smart city, the government needs a progressive way of thinking to optimize and to integrate technology, information and communication. When digitalization and implementation of new technology arrived, the use of ICT in the completion 
of public services is truly needed. This phenomenon has become the engine of the changes on service's distribution.

Digitalization changed, arranged, produced and gave more effective and efficient public services. The arrival of a powerful of second wave of a digital-era changes inside government, responding to the emergence of social-web cloud computing, apps development and many other recent phenomena which support industrial societies further towards an online civilization [5].

Considering this phenomenon, the government of South Tangerang City is committed to implement the strategy of smart city through various digital public services. The use of these services is one of the efforts mentioned in regional long-term plan of Government of South Tangerang City for the assignment period of 2016-2021. It has also been cited in their vision and mission to help society.

Digital public service consist of service which is based on digital application consisting of varied applications and sites. It allows society to access the information, civil registration services and other services such as business license and payment of taxes. This digitalized application has given the possibility to access government services anytime and anywhere. However, some challenges have emerged in the process. Trust, as one of the crucial elements of the acceptance and use of government technology has become a challenge which must be seriously anticipated [6], [7]. Warkentin et al. [8] has conducted a survey showing $87.8 \%$ of society believe that trust in the internet is main factor which facilitates the acceptance of technology provided by the government.

Another result has revealed that the acceptance of technology will be successful and its frequency of use will increase in number when society has the adequate trust in the internet as a medium of transaction [6]. This study has the objective to test the model of UTAUT2 of Venkatesh [3] with trust as additional variable [6]. This study tried to fill the gap in the study of Venkatesh et al. [3] by recommending future study which will be able to test the model of UTAUT2 in various technologies and identifying other relevant factors. This will multiply the number of UTAUT implementation in varied context of the use of technology through experiment which manipulate further predictor.

Our work makes two main contributions to the enrichment of the theoretical body of literature in the acceptance and use of technology context. First, the research model allows us to identify that the constructs of UTAUT2 influence the acceptance and use of digital public service of Government of South Tangerang City. Second, we develop a research model that integrates UTAUT and trust. We analyse how the trust with UTAUT increases the intention to acceptance and to use digital public service of Government of South Tangerang City. Moreover, this study yields insights for local governments seeking to implement or extend the scope of acceptance and use of digital public service.

\section{Materials and methods}

\subsection{Digital public service}

Digital public service is a transformation towards more effective, efficient and accurate public services in order to maintain the relation between government and society [9]. The term digital is a tendency emerging from digitalization of technology which was integrated to all daily life aspects [10].

\subsection{Trust}

Public trust in government related to public assessment is based on their perception on how the authority, the government and political institution use their integrity and political 
power to provide services expected by their people [6]. In the context of technology, trust has the relation with the power of technology in the term of task completion, recommendation needed to accomplish the tasks and consistent cooperation in a predicted manner [11]. Amagoh [6] identified trust as powerful factor in the acceptance of technology, in the term of privacy and security of information. Trust is important element of e-government diffusion and it facilitates the acceptance and use of technology [7].

\subsection{The unified theory of acceptance and use of technology (UTAUT)}

UTAUT2 offers many advantages compared to other models. It has a comprehensive theoretical framework which is supported by variables of the use of technology. It also integrates new variables, relation and strong validity in varied major studies [12]. In earlier version, Venkatesh [3] founded that performance expectancy, effort expectancy and social influence were the constructs which directly influenced behavioural intention in significant way. While facilitating condition and behaviour intention has become direct determinants towards the use of technology.

Venkatesh et al. [7] has developed this earlier version into the model of UTAUT 2 by adding hedonic motivation, price value and habit. Gender, age, and experience played role as moderators. Venkatesh also removed the voluntary use which was a part of the first model of UTAUT. This change was implied to UTAUT applications in the term of voluntary use of technology [7].

To ensure the validity of UTAUT, this model has been empirically examined. This model was recognized more effective in explaining $70 \%$ user's variance compared to other eight models [3]. However, this model does not observe trust as variable. Trust as variable is highly considered to have great implication towards the acceptance of technology. Persaud and Sehgal [13] have proved that trust is powerful determinant by exploring its function in egovernment services using the model which combined the elements of UTAUT and theory of diffusion-innovation.

The significance of trust as construct can be seen through the trust of people which can directly affect their decision for purchasing, using or declining a technology. In order to see its implication on the acceptance and use of technology, this research has inserted trust into the model of UTAUT 2.

Mayor hypotesis proposed in this study are:

H0: The constructs of model UTAUT 2 and trust did not influence the acceptance and use of digital public services

H1: The constructs of model UTAUT 2 and trust influenced the acceptance and use of digital public service

Minor hypotesis proposed in this study are:

H1: Gender and age have moderated the influence of performance expectancy towards behavioral intention to use digital public service.

$\mathrm{H} 2$ : Gender, age and experience have moderated the influence of effort expectancy towards behavioral intention to use digital public service.

H3: Gender, age and experience have moderated the impact of social influence towards behavioral intention to use digital public service.

H4: Gender, age and experience have moderated the influence of facilitating conditions towards behavioral intention to use digital public service.

H5: Age and experience have moderated the influence of facilitating conditions towards behavioral intention to use digital public service.

H6: Gender, age and experience have moderated the influence of hedonic motivation towards behavioral intention to use digital public service. 
H7: Gender and age have moderated the influence of price value towards behavioral intention to use digital public service.

H8: Gender, age and experience have moderated the influence of habit towards behavioral intention to use digital public service.

H9: Gender, age and experience have moderated the influence of habit towards the use behaviour of digital public service.

H10: Experience has moderated the influence of behavioural intention towards the use behavior of digital public service

H11: Trust influenced behavioural intention to use digital public services.

\section{Methods}

The research employed quasi-experimental design which used non equivalent control group to compare the behavior of two different groups. This research measured the group of experiment and control using different treatment. The controlled group consisted of users who have used digital public services while another group consisted of users who never use this service.

The participants were sought through announcements of participant's recruitment which were spread in government offices of South Tangerang and also in some universities. The information regarding participant's recruitment was also distributed through whatsapp platform.

The participants followed the quasi-experiment procedure voluntarily. There were two criterion of recruitment.: (1) The inhabitant of South Tangerang City and this must be proven through national identity card. (2) The use of software to access the internet, either through smart phone or laptop. This is because some digital public service requires the national identity number.

A pre-test was conducted to start the experiment and the treatment was given as the continuity. As the closing process, the post-test has been organized. Following the recommendation from Roscoe's Simple Rules of Thumb [14] each group was formed by thirty participants.

According to the gender classification, this research consisted of 59,4\% male participant and 40,6\% female participants. Majority of participants were of the age of 31 years with 17 years as the youngest participant and 50 years as the oldest. From educational background, $46,9 \%$ of participants were undergraduate students, $9,4 \%$ of participants were postgraduate students, $37,5 \%$ of participants graduated from high school and 6,3\% had diploma certificate.

The controlled group had one to twelve hours to access the internet. From this allocated timing, 33,3\% of participants used the internet within one to three hours, three participants used the internet for seven hours and $36,7 \%$ used the internet for the duration more than seven hours.

The model of this research has been shown in picture no.1 and it has been measured through Structural Equation Modelling (SEM) with PLS (Partial Least Square). The research employed the software of Smart PLS 3.2.7 [15]. The reliability and validity of data was analyzed with software SPSS. 


\section{Results}

Data analysis using SEM consisted of two models; measurement analysis and structural model analysis.

\section{Measurement analysis}

This model focuses on the measurement of validity and reliability of the entire latent constructs of the model proposed [16]. Table 1 has explained data's reliability using loading factor or correlation between indicators and latent constructs. All constructs along with questioner items must reach level 0.7 [17]. It has also been supported with the value of composite reliability. Composite reliability refers to combination of the entire item in order to represent variables. Cronbach Alpha of at least 0.7 indicates that the combination of item has acceptable reliability [18].

Convergent validity is evaluated through Average Variance Extracted and the value of at least 0,5 is accepted. Table 1 shows coefficient of $\alpha$ Cronbach, composite reliability and AVE. The measurement of discriminant validity based on Fornell-Larcker. According to this criterion, Table 2 has shown that the entire constructs of this research has met the value of discriminant validity.

The next step is to see the presence of Common Method Bias (CMB) through Variance Inflation Factor (VIF). Variables must be tested in order to see any correlation among free variable in multiple regression model. All indicators must have value of VIF below 5.0 to meet the requirement of multicollinearity test. Table 3 has presented the measurement result.

All the result in this measurement analysis ensured that the measurement model has been completed. With this completion, evaluation on structural model can be done as the next step of analysis.

Table 1 Loadings Factor (LA), AVE, Composite Reliability, and Cronbach's Alfa Performance Expectancy

\begin{tabular}{ll}
\hline LA PE1 & 0.705 \\
\hline LA PE2 & 0.792 \\
\hline LA PE3 & 0.546 \\
\hline LA PE5 5 & 0.725 \\
\hline AVE & 0.846 \\
\hline CR & 0.533 \\
\hline CA & 0.861 \\
\hline Effort Expectancy & 0.784 \\
\hline LA EE1 & \\
\hline LA EE2 & 0.843 \\
\hline LA EE3 & 0.884 \\
\hline LA EE4 & 0.811 \\
\hline LA EE6 & 0.527 \\
\hline AVE & 0.769 \\
\hline CR & 0.882 \\
\hline CA & 0.706 \\
\hline
\end{tabular}




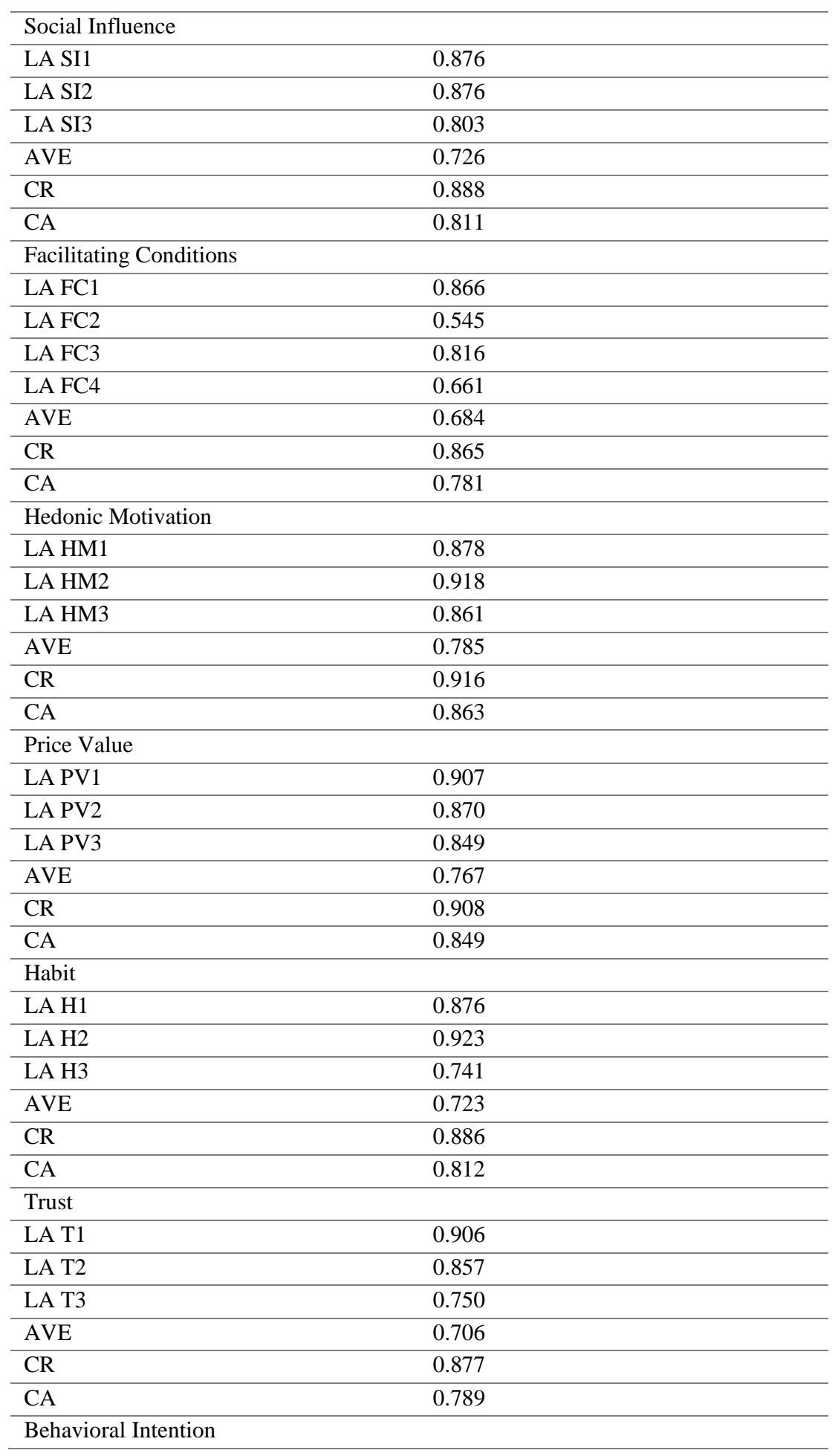




\begin{tabular}{ll}
\hline LA BI1 & 0.878 \\
\hline LA BI2 & 0.938 \\
\hline LA BI3 & 0.873 \\
\hline AVE & 0.804 \\
\hline CR & 0.925 \\
\hline CA & 0.877 \\
\hline
\end{tabular}

Table 2 Discriminant validity - Fornell-Larcker criterion

\begin{tabular}{llllllllll}
\hline & FC & PE & EE & H & T & HM & BI & PV & SI \\
\hline FC & 0.827 & & & & & & & & \\
PE & 0.481 & 0.780 & & & & & & & \\
EE & 0.613 & 0.503 & 0.840 & & & & & & \\
H & 0.672 & 0.448 & 0.596 & 0.850 & & & & & \\
T & 0.652 & 0.411 & 0.652 & 0.762 & 0.840 & & & & \\
HM & 0.527 & 0.754 & 0.599 & 0.599 & 0.402 & 0.886 & & & \\
BI & 0.460 & 0.610 & 0.630 & 0.664 & 0.543 & 0.624 & 0.897 & & \\
PV & 0.227 & 0.668 & 0.503 & 0.623 & 0.610 & 0.584 & 0.590 & 0.876 & \\
SI & 0.238 & 0.429 & 0.284 & 0.607 & 0.417 & 0.402 & 0.516 & 0.601 & 0.852 \\
\hline
\end{tabular}

Table 3 Colinearity Statistics VIF

\begin{tabular}{|c|c|c|}
\hline \\
\hline Latent Variabel & Indicator & VIF \\
\hline \multirow[t]{4}{*}{ Performance Expectancy } & PE1 & 1.330 \\
\hline & PE2 & 1.702 \\
\hline & PE4 & 2.597 \\
\hline & PE5 & 3.345 \\
\hline \multirow{5}{*}{ Effort Expectancy } & EE1 & 2.418 \\
\hline & EE2 & 3.795 \\
\hline & EE3 & 2.796 \\
\hline & EE5 & 2.212 \\
\hline & EE6 & 2.969 \\
\hline \multirow[t]{3}{*}{ Social Influence } & SI1 & 2.616 \\
\hline & SI2 & 2.662 \\
\hline & SI3 & 1.381 \\
\hline \multirow[t]{3}{*}{ Facilitating Condition } & $\mathrm{FC} 1$ & 1.609 \\
\hline & $\mathrm{FC} 2$ & 1.805 \\
\hline & FC3 & 1.540 \\
\hline \multirow[t]{3}{*}{ Hedonic Motivation } & HM1 & 2.078 \\
\hline & HM2 & 2.816 \\
\hline & HM3 & 2.173 \\
\hline \multirow{3}{*}{ Price Value } & PV1 & 2.539 \\
\hline & PV2 & 1.822 \\
\hline & PV3 & 2.190 \\
\hline \multirow[t]{3}{*}{ Habit } & $\mathrm{H} 1$ & 2.028 \\
\hline & $\mathrm{H} 2$ & 2.179 \\
\hline & $\mathrm{H} 3$ & 1.525 \\
\hline \multirow[t]{3}{*}{ Trust } & $\mathrm{T} 1$ & 2.343 \\
\hline & $\mathrm{T} 2$ & 2.001 \\
\hline & $\mathrm{T} 3$ & 1.418 \\
\hline \multirow{3}{*}{ Behavioral Intention } & BI1 & 2.498 \\
\hline & $\mathrm{BI} 2$ & 3.468 \\
\hline & $\mathrm{BI} 3$ & 2.203 \\
\hline
\end{tabular}




\section{Structural model analysis}

The evaluation on structural model was conducted to obtain path coefficient value $(\beta)$ and determinant coefficient value $\left(\mathrm{R}^{2}\right)$. Path coefficient value which is at the range -0.1 to 0.1 was considered as value which did not have any influence. The value of $\mathrm{R}^{2}$ has been defined as a requirement of endogenous construct's measurement. $\mathrm{R}^{2}$ of the entire construct can be seen on the table 4 . The changes of $\mathrm{R}^{2}$ value can be employed to see the impact of latent-exogenous variable towards latent-endogenous variable having substantial influence.

Table 4 Determination coefficient $\mathrm{R}^{2}$

\begin{tabular}{ll}
\hline Endogenous construct & $\mathrm{R}^{2}$ \\
\hline Behavioral Intention & 0,993 \\
Use Behavior & 0,211 \\
\hline
\end{tabular}

The last step is the use of Standardized Root Mean Square Residual (SRMR). SRMR is an absolute measure of fit and it is defined as the standardized difference between the observed correlation and the predicted one [19]. It has also been used to avoid any mistake of model specification. This research utilized SRMR and Normed Fit Index (NFI). The value of SRMR is accepted when it is below 0.08 while the value of NFI value is above 0.90 [20]. The result of this research indicated that the model of this research is not fit with value of SRMR 0.301 and NFI 0.124.

From eleven minor hypotheses proposed, there were nine hypotheses which were accepted $(\mathrm{H} 1, \mathrm{H} 2, \mathrm{H} 3, \mathrm{H} 4, \mathrm{H} 5, \mathrm{H} 7, \mathrm{H} 8, \mathrm{H} 10$ and $\mathrm{H} 11)$. The result revealed that performance expectancy had negative impact towards behavioural intention of use with $\beta$ value -0.647 . However, as moderator, gender and age were able to moderate the impact of performance expectancy towards behavioural intention of use with $\beta$ value 2.936 and 2.091 .

Effort expectancy had positive influence on behavioural intention of use and it can be seen from $\beta$ value 0.577 . As moderator, age, gender and experience have moderated the influence of effort expectancy towards behavioural intention of use with $\beta$ value $0.811,0.795$ and 0.751. Social influence also had the impact towards behavioural intention of use. Age, gender and experience were also able to moderate social influence with $\beta$ value $0.625,0.685$ and 0.59 .

Facilitating condition had positive impact towards behavioural intention of use by showing $\beta$ value 0.245 . This variable had negative impact towards the use of digital public service and it can be seen from $\beta$ value $-0,468$. As moderator, gender, age and experience were able to moderate the impact of facilitating condition in using digital public service with $\beta$ value 1,454 , $-1,679$, and 0,877 .

Hedonic motivation did not give any impact on intention of use with $\beta$ value 0,014 . However, as moderator, gender, age and experience have moderated the impact of hedonic motivation on the intention of use. Price value has influenced the intention of use and it can be seen from $\beta$ value 0.626 . The influence of price value has been moderated by gender and age with $\beta$ value -0.762 and -1.340 .

Habit had positive impact towards behavioural intention of use with $\beta$ value 0,458 . Gender and age have moderated the impact with $\beta$ value 1.012 and 2.662. However, as moderator, experience did not moderate the impact of behavioural intention of use and it has been shown through $\beta$ value -0.074 .

Towards the use of digital public service, habit did not have any impact with $\beta$ value 0.030 . Moreover, gender and age as moderator, they did not also moderate the impact of habit towards the use of digital public service. Trust had negative influence towards behavioural intention of use and it has been indicated through $\beta$ value -0.471 . Behavioural intention of use had significantly influenced the use of digital public service with $\beta$ value 0.356 . 
Experience as moderator, it has enhanced the influence of behavioural intention of use with $\beta$ value 0,821 .

\section{Discussion}

The research was aimed to verify the model of UTAUT 2 with trust in the internet as additional variable. Trust in the internet is considered as a factor which influences the acceptance and use of digital public service of inhabitant of South Tangerang City. Hypotheses have been tested in the previous part and the findings were revealed. This part discusses further explanation about the findings connected to the theory.

Firstly, the findings of this research have indicated that hedonic motivation was the only variable which did not influence the intention of use which may later on affect use behaviour of digital public service of government of South Tangerang City.

As an additional construct, trust was able to influence the intention of use of digital public service. Behaviour intention also had significant influence on the use of this service. Moreover, the findings have shown that gender, age and technical infrastructure and services which have been provided by their government. They consider that these supports are absolutely needed to support the use of technology and this thought is positively appreciated thanks to high intention to adopt it. This result went along with the finding of previous research of Venkatesh et al. [3] portraying that facilitating condition and the use of technology had strong relation.

According to statistical analysis, performance expectancy had negative influence on the intention of use of digital public service. This result has shown that users considered that the use of digital public service was useful in their daily life. It had increased the probability to achieve the goals even though it did not increase the use of it. This result supported the result of previous research stating that performance expectancy correlated with the adoption of egovernment even though it was not a significant correlation [21].

Other finding has revealed that effort expectancy significantly influenced the intention of use. Venkatesh et al. [3] also mentioned the importance of effort expectancy at initial process of the acceptance of technology. Effort expectancy related to the ease of use. Society had positive point of view regarding the ease to access digital public service in order to enhance their intention to use it.

Social influence has been defined as changes in thought, feeling, attitude or behaviour and these changes were the result of interaction with individual or with other group [22]. In this research, social influence refers to the individuals having the capability to influence others to use public services based on digitalized technology.

The result of statistical analysis has revealed that social influence had negative impact on the intention of use. Even though closed knit society or strong influencers have accessed this service, the intention of use was still at low level. Supporting this result, Venkatesh et al. [3] stated that social influence will significantly affect behavioural intention when the use of that technology is obligatory. The intention was at low level because of the nature of the use of this service which was voluntary.

Facilitating condition refers to how the individual consider that technical infrastructure and other facilities have been provided by the institution. The inhabitants of South Tangerang City have positive consideration on the support the use of technology and this thought is positively appreciated thanks to high intention to adopt it. This result went along with the finding of previous study of Venkatesh et al. [3] potraying that facilitating condition and the use of technology had strong relation.

Statistical analysis has been revealed that hedonic motivation did not influence the intention of use. Therefore the hypothesis on the influence of hedonic motivation towards the intention of use was rejected. People thought that hedonic motivation did not affect their intention to 
use digital public service. This result did not match with the finding of Venkatesh et al. [7] which stated that technology adoption can be explained in a better way if it is integrated with the factors affecting hedonic motivation itself, such as the pleasure that they feel.

Venkatesh et al. [7] stated that price and cost have significant impact on the use of technology. The statistical result of this research has indicated the same finding. Price value influenced significantly the intention of use. This finding indicated that the value of digital public service and the entire cost which has been charged from inhabitant were worthwhile. In fact, the use of this digital service is cost-free and the people can access all services provided. Price value of this service has been viewed from the money spent for internet and the benefits obtained by accessing this service.

Some previous researches stated that habit influenced directly the use of technology [23]. The result of this research did not match with those previous researches due to the habit of using that service. The frequency of use did not increase since people have considered the use of that service as habit, routine and obligation. Inhabitants of South Tangerang City are used to access government services using the same digital service.

As additional variable, trust in e-government context has been defined as people perception that e-government websites have important attributes to keep individual's intention alive and also follow the set of the values that they respect [24]. Trust refers to the belief on egovernment websites which are able to provide services needed by the society in a consistent way and give the utmost benefit to the society, for example proper use of data and data protection [7]. For example, SIAKCAPIL, information system related to civic registering process covering inhabitant registration process and civic registration, there are several data used such as number of civil registration, family card and national identity card. Those data are confidential as they are related to finance, personal information and safety. Therefore, trust has been considered as an important element and it affects the intention of using digital public service.

Findings revealed by Raman and Don states that the intention of use influences the use of technology significantly. As moderator, experience has moderated the influence of this intention. This finding has shown that the repetition of use will enhance the intention to use this digital public service.

\section{Conclusion}

The results of this study indicate that of the seven constructs of the UTAUT 2 model, performance expectations, business expectations, social influence, supporting facilities, hedonic motivation, price values and habits, only hedonic motivation does not affect the intention to use the digital public service usage of South Tangerang City Government . Thus there are six constructs that influence behavioral intentions in using digital public services of the South Tangerang City Government, namely performance expectations, business expectations, social influence, supporting facilities, price values and habits. An additional construct is that trust is proven to have an influence on the intention to use digital public services. Likewise, behavioral intention to use has a significant effect on the behavior of using digital public services. In addition, the results of this study also indicate that moderator variables namely gender, age, and experience moderate the influence of exogenous variables on endogenous variables namely intention to use and usage behavior.

The UTAUT 2 model is not fully implemented in the digital public service acceptance and use model of the South Tangerang City Government. With the model not implied, the final model of this study consists of seven constructs namely performance expectations, business expectations, social influence, supporting facilities, price values, habits and beliefs that 
influence the intention to use digital public service usage behavior and are moderated by age, gender and experience.

\section{Acknowledgements}

This work was supported by local research funding in 2019, namely Publikasi Internasional Terindeks Mahasiswa Magister (PITMA-B) Universitas Indonesia. The research title is "Penerimaan dan Interaktivitas dalam Penggunaan Teknologi Komunikasi Digital." The grant number is NKB-1003/UN.2.R3.1/HKP.05.00/2019

\section{References}

[1] F. D. Davis, R. P. Bagozzi a P. R. Warshaw, „User acceptance of computer technology: A comparison of two theoretical models,“" Management Science, pp. 982-1003, 1989.

[2] I. Ajzen, „The Theory of Planned Behavior,“ Organizational Behavior and Human Decision Processes, pp. 179-211, 1991.

[3] V. Venkatesh, M. G. Morris, G. B. Davis a F. D. Davis, „User acceptance of information technology: toward a unified view,“ MIS Quarterly, zv. 27, \%1. vyd.3, pp. 425-478, 2003.

[4] M. A. Firdaus, Irwansyah a K. Djaja, „Mobile apps as government communication media in urban public services: case study - the usage of Qlue application by Jakarta Provincial Government,“" Transaction on Ecology and The Environment, pp. 417-429, 2016.

[5] P. Dunleavy, Digital Era Governance, Oxford: Oxford University Press, 2006.

[6] F. Amagoh, „Determinants of e-government diffusion in Nigeria: An examination of theoretical models,“ Information Development, zv. 32 (4), pp. 1137-1154, 2016.

[7] V. Venkatesh, J. Y. Thong, F. K. Chan a P. J. Hu, „Managing Citizens' Uncertainty in EGovernment Services: The Mediating and Moderating Roles of Transparency and Trust.," Information Systems Research, pp. 87-111, 2016.

[8] M. Warkentin, D. Gefen, P. Pavlou a M. Rose, „Encouraging Citizen Adoption of eGovernment by Building Trust,“ Electronic Markets, pp. 157-162, 2002.

[9] Adobe, Global Survey Results and Insights On Digital Citizen Services, San Fransisco: Adobe, 2016.

[10] O. Ruud, Successful digital transformation projects in public sector with focus on municipalities, France: SKEMA Business School, 2017.

[11] D. H. McKnight, M. Carter, J. B. Thatcher a P. F. Clay, „Trust in a specific technology: an investigation of its components and measures," Transactions on Management Information Systems, pp. 1-15, 2011.

[12] Morosan a DeFranco, „It's about time: Revisiting UTAUT2 to examine consumers' intentions to use NFC mobile payments in hotels, “ International Journal of Hospitality Management, pp. 17-29, 2016.

[13] A. Persaud a P. Sehgal, „Attitudes and perceptions of Canadians towards e-government,“ rev. International Conference on e-Government, Boston, 2009.

[14] J. Roscoe, Fundamental Research Statistics for The Behavioural Sciences (2nd Edition ed.), New York: Holt Rinehart \& Winston, 1975. 
[15] C. M. Ringle a D. d. Silva, „Structural Equation Modeling With The Smartpls,“ Revista Brasileira De Marketing, pp. 56-73, 2014.

[16] C. Fornell a D. F. Larcker, „Evaluating Structural Equation Models with Unobservable Variables and Measurement Error.,“ Journal of Marketing Research, pp. 39-50, 1981.

[17] J. F. Hair, W. C. Black, B. Babin a R. E. Anderson, Multivariate Data Analysis. Seventh Edition., New Jersey: Prentice Hall, 2010.

[18] D. George a P. Mallery, PSS for Windows Step by Step: A Simple Guide and Reference, Boston: Allyn \& Bacon, 2003.

[19] R. M. Baron a D. A. Kenny, „The Moderator-Mediator Variable Distinction in Social Psychological Research: Conceptual, Strategic, and Statistical Considerations,“ Journal of Personality and Social Psychology, zv. 51, \%1. vyd.6, pp. 1173-1182, 1986.

[20] Gmbh, „www.smartpls.com,“ [Online]. Available: www.smartpls.com. [Cit. 52 2019].

[21] S. H. Al-Shafi, Factors Affecting E-government Implementation and Adoption in the State of Qatar, London: Brunel University, 2009.

[22] G. V. Lorenz a K. Buhtz, „Social Influence In Technology Adoption Research: A Literature Review And Research Agenda,“ 25th European Conference on Information Systems, pp. 2331-2351, 2017.

[23] M. Limayem, S. G. Hirt a C. M. Cheung, „How habit limits the predictive power of intention: The case of information systems continuance.,“ MIS Quarterly, pp. 705-737, 2007.

[24] R. C. Mayer, J. H. Davis a F. D. Schoorman, „An integrative model of organizational trust,“"Academy of Management Review, zv. 20, pp. 709-734, 1995. 